\title{
PENILAIAN PELAKSANAAN PENDIDIKAN KESEHATAN BERDASARKAN PEDOMAN PELAKSANAAN UKS DAN OTTAWA CHARTER
}

\author{
Assessment of Health Education Implementation Based on Guidelines FOR \\ Implementing UKS and Ottawa Charter
}

\author{
1'Intan Putri Rahayu, ${ }^{2}$ Fika Ardiana, ${ }^{3}$ Inriza Yuliandari, ${ }^{4}$ Wahyu Febriawan, \\ 5Jayanti Dian Eka Sari \\ 12345Departemen Promosi Kesehatan dan Ilmu Perilaku, Program Studi Kesehatan \\ Masyarakat, Fakultas Kesehatan Masyarakat PSDKU Universitas Airlangga Banyuwangi \\ intan.putri.rahayu-2015@fkm.unair.ac.id
}

\begin{abstract}
Health is the most important thing that must be known by many people. Awareness of the importance of health needs to be instilled early on so that children can easily apply it in their lives. To support this, the government launched a health promotion program in schools. Health promotion is the way in which efforts can be made to improve public health and the environment in the community. Many ways can be done so that people can do disease prevention, one of them is by applying health education. Health education is an effort to provide guidance to learners about health covering physical, mental and social aspect in order to improve and develop with good knowledge, attitude, and practice related to healthy life principle. Base on of this background, the authors do research to determine the state of health education in schools. The purpose of this research is to know the implementation of health education in the educational institution in accordance with the guidelines of the implementation of UKS and Ottawa Charter. The method of implementation of this activity is to use interview techniques and practices based on an instrument that has been validated by researchers along with supervisors. This activity was conducted on May 2nd, 2018 for 10 respondents, one coach, four students, and five members of the Red Cross Teen. The institution that researchers chose was SMP Negeri 1 Giri Banyuwangi. The conclusion of this study indicates that the implementation of health promotion in SMP Negeri 1 Giri Banyuwangi still not in accordance with the Guidelines for Implementation of UKS in School Year 2014, so the result of this research can be used as advocacy material to SMP Negeri 1 Giri Banyuwangi.
\end{abstract}

Keywords: Health Promotion, Health Education, UKS, and Ottawa Charter

\begin{abstract}
Abstrak
Kesehatan adalah hal penting yang harus diperhatikan oleh banyak orang. Kesadaran akan pentingnya kesehatan perlu ditanamkan sejak usia dini agar anak-anak dapat dengan mudah mengaplikasikannya di kehidupan mereka. Untuk mendukung hal tersebut, pemerintah mencanangkan program promosi kesehatan di sekolah. Promosi kesehatan adalah suatu cara yang dilakukan agar dapat melakukan pencegahan terhadap penyakit sehingga meningkatkan derajat kesehatan diri dan lingkungan di masyarakat. Banyak cara 12345 Intan Putri Rahayu, Fika Ardiana, Inriza Yuliandari, Wahyu Febriawan, Jayanti Dian Eka Sari adalah Departemen Promosi Kesehatan dan Ilmu Perilaku, Program Studi Kesehatan Masyarakat, Fakultas Kesehatan Masyarakat PSDKU Universitas Airlangga, Banyuwangi
\end{abstract}


yang dapat dilakukan agar masyarakat dapat melakukan pencegahan penyakit, salah satunya adalah dengan melaksanakan pendidikan kesehatan. Pendidikan kesehatan adalah upaya yang diberikan berupa bimbingan kepada peserta didik tentang kesehatan yang meliputi aspek fisik, mental dan sosial agar kepribadiannya dapat tumbuh dan berkembang dengan baik melalui peningkatan pengetahuan, keterampilan, penanaman kebiasaan hidup sehat, terutama melalui pemahaman konsep yang berkaitan dengan prinsip hidup sehat. Berdasarkan latar belakang tersebut, penulis mengadakan penelitian untuk mengetahui keadaan pendidikan kesehatan di sekolah. Tujuan diadakannya penelitian ini adalah untuk mengetahui pelaksanaan promosi kesehatan di institusi pendidikan sesuai dengan pedoman pelaksanaan UKS dan Ottawa Charter. Metode pelaksanaan kegiatan ini adalah dengan menggunakan teknik wawancara dan observasi berdasarkan instrumen yang telah divalidasi oleh peneliti bersama dosen pembimbing. Kegiatan ini dilakukan pada tanggal 2 Mei 2018 dan dilakukan kepada 10 responden, dengan rincian; satu pembina, empat siswa, dan lima anggota Palang Merah Remaja. Institusi yang penulis pilih adalah SMP Negeri 1 Giri Banyuwangi. Kesimpulan dari penelitian ini menunjukkan bahwa pelaksanaan promosi kesehatan di SMP Negeri 1 Giri Banyuwangi masih belum sesuai dengan Pedoman Pelaksaan UKS di Sekolah Tahun 2014, sehingga hasil dari kegiatan ini dapat digunakan sebagai bahan advokasi kepada pihak SMP Negeri 1 Giri Banyuwangi agar selanjutnya pihak sekolah dapat menerapkan pendidikan kesehatan sebagai aspek penting dalam Trias UKS dengan lebih baik.

Kata kunci : Promosi Kesehatan, Pendidikan Kesehatan, UKS, dan Ottawa Charter

\section{PENDAHULUAN}

\section{Menurut Undang Undang No 36 \\ Tahun 2009 tentang kesehatan, kesehatan adalah suatu kondisi sehat, baik secara mental, fisik, sosial, dan spiritual sehingga setiap orang dapat hidup produktif. Hal tersebut juga sejalan dengan pengertian kesehatan menurut WHO (1948), bahwa kesehatan merupakan hak dasar bagi setiap orang tanpa melihat asal usul orang tersebut. Tingginya tingkat kesehatan yang dimiliki setiap orang dipengaruhi oleh perilaku yang dilakukan setiap orang dalam kehidupan sehari-harinya.}

Menurut Notoatmojo (2010), kesehatan terdiri atas tiga domain yang bermanfaat untuk mengetahui seberapa besar tingkat perilaku sehat setiap individu, yaitu pengetahuan terhadap kesehatan (health knowledge), sikap terhadap kesehatan (health attitude), dan praktik atau tindakan kesehatan (health practice). Pertama, pengetahuan terhadap kesehatan, yaitu segala informasi yang diketahui oleh setiap individu tentang cara meningkatkan dan memelihara kesehatan pada diri setiap individu. Kedua, sikap terhadap kesehatan, yaitu penilaian individu atas hal-hal yang berhubungan dengan cara memelihara kesehatan. Ketiga, praktik atau tindakan kesehatan yang merupakan tindakan yang dilakukan individu yang terdiri dari kegiatankegiatan yang bertujuan untuk memperoleh kehidupan yang sehat.

Strategi promosi kesehatan merupakan cara atau langkah yang diperlukan untuk mencapai, memperlancar atau mempercepat pencapaian tujuan promosi kesehatan, salah satunya yaitu dengan strategi promosi kesehatan Ottawa Charter. 
WHO (1986) menyebutkan bahwa Ottawa Charter memiliki lima sarana aksi yang perlu dijalankan untuk membangun strategi promosi kesehatan yang baik. Sarana aksi tersebut adalah membangun kebijakan yang berwawasan kesehatan, menciptakan lingkungan yang mendukung, memperkuat gerakan masyarakat, mengembangkan keterampilan individu, dan reorientasi pelayanan kesehatan. Kelima sarana tersebut merupakan hasil dari konferensi internasional di bidang promosi kesehatan yang dilakukan di Ottawa pada tahun 1986.

Menurut tujuan Indonesia sehat 2010, terdapat paradigma sehat yang terdiri dari tiga unsur, yaitu lingkungan sehat, perilaku sehat, dan pelayanan kesehatan yang bermutu, adil dan merata. Perilaku sehat ini merupakan perilaku yang digunakan untuk memelihara, meningkatkan kesehatan, menghindari atau mencegah terjadinya penyakit, melindungi diri dari berbagai macam penyakit, dan ikut serta dalam meningkatkan kualitas kesehatan (Depkes RI, 2013). Program perbaikan tidak hanya sebatas pada lingkungan sehat dan pelayanan kesehatan, tetapi juga memperhatikan faktor perilaku. Hal ini disebabkan faktor perilaku dapat menjadi faktor terjadinya berbagai penyakit, baik penyakit menular maupun penyakit tidak menular.

Kualitas dari setiap sumber daya manusia (SDM) ditentukan oleh dua faktor yang saling berhubungan dan berkaitan. Faktor tersebut terdiri dari pendidikan dan kesehatan. Kesehatan adalah syarat utama dalam memperoleh keberhasilan upaya pendidikan, sedangkan pendidikan merupakan salah satu faktor untuk tercapainya status kesehatan yang tinggi dari setiap individu (Maryunani, dkk, 2012 dan Henico Putri Lina, 2016). Untuk menciptakan SDM yang berkualitas dan mampu bersaing, perlu adanya tindakan pembekalan pengetahuan mengenai kesehatan. Pembekalan tersebut dapat dimulai dari usia dini, yaitu usia anak sekolah. Mulai dari tingkat pra sekolah, SD, SMP, dan SMA. Pada usia ini, anak akan belajar langsung dari lingkungannya. Lingkungan disini dapat diartikan sebagai orang tua, guru, dan teman sepermainan. Mereka dapat mempelajari bagaimana harus bertingkah laku yang sesuai dan tidak sesuai dengan aturan.

Undang-Undang RI No.36 tahun 2009 bab VI pasal 79 Ayat, tentang Upaya Kesehatan menjelaskan bahwa upaya pembinaan kesehatan di lingkungan sekolah diselenggarakan dengan tujuan untuk meningkatkan dan mengembangkan kemampuan hidup yang lebih sehat oleh siswa. Kemampuan tersebut harus diterapkan dalam lingkungan kehidupan yang sehat, sehingga anak usia sekolah dapat belajar, tumbuh, berkembang dan memperoleh derajat kesehatan setinggi-tingginya agar menjadi SDM yang berkualitas. Melihat pentingnya kesehatan dalam kehidupan manusia, pemerintah mencanangkan program promosi kesehatan di sekolah agar anak-anak sejak dini mengerti akan pentingnya. Program tersebut biasa dikenal dengan sebutan UKS (Usaha Kesehatan Sekolah). UKS adalah bagian dari program kesehatan anak usia sekolah. Kegiatan ini merupakan salah satu upaya terpadu antara lintas program dan lintas sektor. UKS dapat dijadikan sebagai tempat pelaksanaan pendidikan dan kesehatan secara bersamaan, terencana dan bertanggung jawab dalam menciptakan, mengembangkan serta melaksanakan kegiatan hidup bersih dan sehat. Kegiatan ini dapat dilakukan oleh siswa, 
guru, dan masyarakat lingkungan sekolah (Depkes RI, 2010).

Pengaplikasian program kegiatan UKS di sekolah dapat diberikan pada tiga kelompok sasaran; sasaran primer, sasaran sekunder, dan sasaran tersier. Sasaran primer pada pembinaan UKS di sekolah adalah siswa sekolah, dimana mereka diharapkan dapat untuk mengetahui dan melaksanakan UKS.Sasaran sekunder adalah orangorang yang mempunyai pengaruh pada sasaran primer dalam mengambil keputusan untuk melaksanakan UKS. Pada UKS di sekolah yang menjadi sasaran sekunder adalah guru, dimana seorang guru adalah panutan dari para siswa. Sasaran tersier adalah orang yang berfungsi untuk mengambil keputusan formal, seperti komite sekolah, kepala desa, lurah, camat, dinas pendidikan, puskesmas dan sebagainya. Mereka dapat memberikan dukungan dalam menentukan kebijakan, pendanaan dalam proses Pembinaan UKS yang akan diberikan kepada siswa sekolah. (Pedoman Pelaksanaan UKS di Sekolah, 2014).

Masalah kesehatan yang sering timbul pada anak usia sekolah yaitu gangguan perilaku, penyakit infeksi, penyakit saluran pencernaan, penyakit saluran pernafasan, penyakit kulit dan malnutrisi. Masalah-masalah tersebut biasanya timbul karena kurangnya fasilitas pelayanan kesehatan di sekolah. Fasilitas dan pelayanan kesehatan di sekolah dapat dilihat melalui kegiatan UKS (Usaha Kesehatan Sekolah).

Keberhasilan pembinaan dan pengembangan Usaha Kesehatan Sekolah (UKS) pada akhirnya akan tercermin pada perilaku hidup sehat dan derajat kesehatan peserta didik, dan ini merupakan dampak yang diharapkan dari keseluruhan pola pembinaan dan pengembangan UKS. Tujuan umum didirikannya Usaha Kesehatan Sekolah (UKS) adalah untuk meningkatkan mutu pendidikan dan prestasi belajar peserta didik dengan meningkatkan perilaku hidup bersih dan sehat serta derajat kesehatan peserta didik dan menciptakan lingkungan yang sehat, sehingga memungkinkan pertumbuhan dan perkembangan yang harmonis dan optimal dalam rangka pembentukan manusia Indonesia seutuhnya. (Pedoman Pelaksanaan UKS di Sekolah, 2014)

Karena pendidikan kesehatan termasuk dalam salah satu aspek Trias Usaha Kesehatan Sekolah (UKS), maka pendidikan kesehatan seharusnya diaplikasikan pada setiap sekolah di Indonesia. Banyaknya konsep pendidikan kesehatan yang belum dimengerti oleh sekolah-sekolah di Indonesia adalah latar belakang pemilihan Penulis dalam mengambil topik penelitian.

\section{METODE}

Penelitian ini dilakukan di SMP Negeri 1 Giri Banyuwangi dengan berfokus pada berbagai kegiatan Unit Kesehatan Sekolah (UKS) dalam hal promosi kesehatan di instansi pendidikan menengah pertama. Metode yang diterapkan oleh penulis dalam penelitian ini adalah dengan menggunakan metode analisis kualitatif deskriptif.

Penelitian tentang pelaksanaan UKS ini dilakukan pada saat kegiatan belajar mengajar aktif yakni tanggal 3 Mei 2018, pukul 09.30 WIB di SMP Negeri 1 Giri Banyuwangi. Sumber informasi dalam penelitian ini adalah data primer berupa observasi lapangan dengan cara memberikan checklist pada instrumen yang telah kami buat, wawancara kepada informan atau 
narasumber dari guru pembina UKS, siswa anggota PMR dan siswa bukan anggota PMR, dan warga sekolah, serta data sekunder berupa dokumen pedoman pelaksanaan UKS di sekolah sebagai rujukan kami untuk membuat instrumen yang kami gunakan.

Penulis memilih SMP Negeri 1 Giri Banyuwangi sebagai sampel yang akan diobservasi dengan alasan karena SMP Negeri 1 Giri Banyuwangi merupakan sekolah milik negara yang memiliki banyak prestasi dengan letak sekolah yang strategis. Penulis ingin mengetahui bagaimana penerapan promosi kesehatan di SMP Negeri 1 Banyuwangi. Penelitian ini bertujuan untuk mengetahui dan mendeskripsikan komponen-komponen yang terkait dengan promosi kesehatan yang ada di SMP Negeri 1 Giri Banyuwangi.

\section{HASIL DAN PEMBAHASAN}

\section{Pelaksanaan \\ Pendidikan Kesehatan \\ Pelaksanaan UKS program} pendidikan kesehatan di SMP Negeri 1 Giri Banyawangi belum sesuai dengan Pedoman Pelaksanaan UKS di Sekolah Tahun 2014 yaitu melalui kegiatan intrakurikuler dan ekstrakurikuler.

Pelaksanaan

$\begin{array}{lcr}\text { kesehatan } & \text { melalui } & \text { kegiatan } \\ \text { intrakurikuler } & \text { yang } & \text { seharusnya } \\ \text { dilakukan } & \text { melalui } & \text { peningkatan }\end{array}$ pengetahuan, keterampilan, penanaman kebiasaan hidup bersih dan sehat, terutama melaui pemahaman konsep yang berkaitan dengan prinsip hidup sehat, mencakup pemahaman pola makan sehat, pemahaman pentingnya keseimbangan gizi pada saat remaja, pemahaman tentang penyakit menular seksual, mengenal bahaya seks bebas, memahami berbagai penyakit menular yang bersumber dari lingkungan yang tidak sehat, mengenal cara untuk menjaga kebersihan alat reproduksi, mengenal bahaya merokok bagi kesehatan, mengenal bahaya mengkonsumsi minuman keras dan narkoba serta mengenal cara menolak ajakan menggunakan narkoba dan cara menolak perlakuan pelecehan seksual.

Pada kegiatan intrakurikuler di SMP Negeri 1 Giri Banyuwangi masih dalam konteks Kegiatan Belajar Mengajar atau KBM didalam kelas yang disampaikan oleh guru. Pendidikan kesehatan yang diperoleh disampaikan secara singkat pada saat kegiatan belajar mengajar oleh guru IPA, sehingga informasi yang didapat siswa hanya sebatas pengetahuan umun pada mata pelajaran IPA, karena belum adanya kurikulum yang membahas secara spesifik tentang standar pendidikan kesehatan yang harus diterima oleh siswa SMP. Guru yang memberikan informasi juga hanya sebatas pengetahuan kesehatan umum dan berdasarkan pengalaman dari guru tersebut, belum adanya modul atau buku saku untuk menunjang pembelajaran tentang pendidikan kesehatan, sedangkan tidak terdapat guru yang memiliki basic kesehatan.

Informasi yang pernah disampaikan guru saat KBM yaitu tentang bahaya jajan sembarang dan pentingnya makan makanan bergizi. Metode yang digunakan oleh guru dan pembina dalam mengajar pendidikan kesehatan yaitu menggunakan belajar kelompok, diskusi, ceramah, bimbingan, dan tanya jawab. Selain itu sekolah memberikan pendidikan kesehatan setiap awal ajaran baru yang diterima oleh peserta didik baru dalam kegiatan Masa Orientasi Siswa (MOS) yang disampaikan oleh Kepolisian Resor Banyuwangi dengan metode ceramah 
setelah upacara. Materi yang disampaikan membahas tentang bahaya narkoba, minum-minuman keras dan tata tertib lalu lintas. Materi yang disampaikan secara umum tidak secara khusus membahas pertopik. Materi tentang kesehatan lainnya yang pernah diterima oleh siswa SMP Negeri 1 Giri Banyuwangi yaitu penyuluhan tentang HIV/AIDS oleh petugas puskesmas yang biasanya diberikan setiap 1 sampai $2 \mathrm{kali}$ setiap tahunnya, untuk materi kesehatan reproduksi, dan lainnya belum pernah mendapatkan penyuluhan atau informasi.

Kegiatan ekstrakurikuler adalah kegiatan yang dilakukan diluar jam pelajaran biasa yang dilakukan disekolah maupun diluar sekolah dengan tujuan antara lain untuk memperluas pengetahuan dan keterampilan peserta didik. Kegiatan ekstrakurikuler yang yang seharusnya dilakukan oleh SMP Negeri 1 Giri Banyuwangi adalah mencakup kegiatan yang berkaitan dengan pendidikan kesehatan di sekolah adalah kegiatan wisata siswa, kemah, mengikuti lomba, melakukan bimbingan untuk hidup sehat, membuat apotik hidup disekolah, membuat kebun sekolah, melakukan kerja bakti, membuat majalah dinding, kegiatan pramuka, PMR, OSIS dan piket sekolah. (Pedoman Pelaksanaan UKS di Sekolah tahun 2014).

Pada kegiatan ektrakurikuler yang ada di SMP Negeri 1 Giri Banyuwangi masih belum terlaksana semua sesuai dengan Pedoman Pelaksanaan UKS di Sekolah tahun 2014. Kegiatan ekstrakurikuler yang terlaksana yaitu terbentuknya PMR, pernah mengikuti lomba PMR tingkat Kecamatan, ada kegiatan pramuka dan kemah (persami) yang dilakukan pada saat Masa Orietasi Siswa oleh peserta didik baru.
Sekolah menerapkan prinsip cinta lingkungan seperti pada saat tahun ajaran baru sekolah mewajibkan murid baru membawa tanaman yang nantinya akan di letakkan di Green House yang merupakan tempat untuk berbagai tanaman di SMP Negeri 1 Giri Banyuwangi dan sebagian akan diletakkan di lingkungan sekolah. Namun sekolah belum memiliki kebun sekolah ataupun apotik hidup, karena tanaman yang ada di dalam green house hanya tanaman bunga saja, belum ada tanaman obatnya. Sekolah juga menanamkan perilaku membuang sampah pada tempatnya dengan menyediakan tempat sampah organik maupun tempat sampah non organik di setiap depan ruang kelas siswa dengan tujuan supaya lingkungan sekolah terbebas dari sampah yang berserakan, namun masih ditemukan sampah di selokan sekolah, dan depan kantin padahal sudah terdapat tempat sampah serta pada beberapa tempat yang tidak terdapat tempat sampahnya. Sekolah melakukan kegiatan kerja bakti setiap hari Jumat atau biasa disebut dengan kegiatan Jumat Bersih dan juga melakukan piket kelas setiap hari.

SMP Negeri 1 Giri Banyuwangi pernah mengadakan lomba kebersihan antar kelas, namun saat ini sudah tidak terlaksana lagi, hal tersebut merupakan penyataan dari ketua PMR 2018. Sekolah juga belum menanamkan perilaku cuci tangan dengan sabun di air mengalir dan sekolah hanya memiliki satu washtafel yang tidak terdapat sabun untuk cuci tangan. Sekolah memberikan mata pelajaran pendidikan jasmani dan olahraga setiap seminggu sekali sesuai dengan jadwal yang sudah ditentukan setiap kelas. 


\section{Media Pendukung Promosi Kesehatan}

Media promosi untuk mendukung pengetahuan siswa tentang kesehatan yang ada di SMP Negeri 1 Giri Banyuwangi hanya terdapat media promosi kesehatan berupa media visual yaitu poster yang terletak dibeberapa dinding sekolah dan di majalah dinding serta sebuah $x$-banner.

Media pendukung sangat membantu dalam proses pembelajaran seperti hasil penelitian Sefti (2014) menunjukkan bahwa peningkatan pengetahuan remaja salah satunya didukung oleh penggunaan media leaflet. Isi leaflet sesuai dengan materi penyuluhan yang disampaikan dengan gambar dan warna serta menyajikan seluruh poin-poin materi pada leaflet.

Media promosi kesehatan yang ada di SMP Negeri 1 Giri Banyuwangi yaitu poster berisi tentang larangan merokok yang berada dibeberapa dinding sekolah, poster larangan membuang sampah sembarangan, poster tujuh langkah cara mencuci tangan, serta terdapat $x$-banner berisi mengenai HIV/AIDS, sedangkan untuk majalah dinding tidak dimanfaatkan untuk kegiatan promosi kesehatan. Belum terdapat pembelajaran seraca khusus maupun poster yang mendungkung pengetahuan siswa terutama dalam hal kesehatan, sehingga masih banyak pendidikan kesehatan yang masih belum mereka terima selama masa sekolah.

Belum adanya pendidikan visual tentang penyakit menular seksual, bahaya seks bebas, penyakit yang bersumber dari lingkungan yang tidak sehat, cara menjaga kesehatan alat reproduksi, serta cara penolak perlakuan pelecehan seksual.

\section{Strategi Promosi Kesehatan Berdasarkan Ottawa Charter}

Strategi promosi kesehatan merupakan langkah untuk mencapai tujuan promosi kesehatan. Langkah untuk membangun strategi promosi kesehatan yang baik, WHO (1986) menyebutkan lima sarana aksi dari Ottawa Charter. Sarana aksi dalam piagam Ottawa Charter yaitu membangun kebijakan berwawasan kesehatan, menciptakan lingkungan yang mendukung, memperkuat gerakan masyarakat, mengembangkan keterampilan individu, dan reorientasi pelayanan kesehatan.

Berdasarkan hasil penelitian ini, yang termasuk dalam lima sarana aksi berdasarkan Ottawa Charter dalam kegiatan intrakurikuler yaitu adanya dukungan dari sekolah dengan mengundang pihak Kepolisian Resor Banyuwangi untuk memberikan informasi mengenai bahaya narkoba, bahaya minum minuman keras dan tata tertib dalam berlalu lintas, serta adanya penyuluhan dari pihak puskesmas tentang HIV/AIDS. Kegiatan intrakurikuler ini belum sepenuhnya menerapkan strategi promosi kesehatan dari Ottawa Charter, masih dalam proses aspek membangun kebijakan berwawasan kesehatan, menciptakan lingkungan yang mendukung, dan mengembangkan keterampilan individu.

Kegiatan ekstrakurikuler yang sudah menerapkan promosi kesehatan dari Ottawa Charter yaitu dengan adanya kegiatan PMR, Pramuka, dan sekolah menerapkan prinsip cinta lingkungan dengan mewajibkan setiap murid baru untuk membawa tanaman, menanamkan perilaku membuang sampah pada tempatnya, namun sekolah belum menanamkan perilaku cuci tangan dengan sabun di air mengalir. Kegiatan ekstrakurikuler ini belum sepenuhnya 
menerapkan strategi promosi kesehatan dari Ottawa Charter, masih dalam proses aspek menciptakan lingkungan yang mendukung dan mengembangkan keterampilan individu.

\section{SIMPULAN}

Berdasarkan hasil penelitian dan pembahasan diatas menunjukkan bahwa pelaksanaan promosi kesehatan di SMP Negeri 1 Giri Banyuwangi masih belum sesuai dengan Pedoman Pelaksaan UKS di Sekolah Tahun 2014. Beberapa dari kegiatan intrakurikuler dan ekstrakurikuler yang belum mendukung pendidikan kesehatan di sekolah. Dari segi sarana aksi Ottawa Charter juga belum dapat diterapkan semua, masih dalam proses aspek membangun kebijakan berwawasan kesehatan, menciptakan lingkungan yang mendukung, dan mengembangkan keterampilan individu.

\section{DAFTAR RUJUKAN}

[1] Departemen Kesehatan Republik Indonesia. (2006). Profil Kesehatan Indonesia 2006. Diakses secara online melalui http://www.depkes.go.id/resource s/download/pusdatin/profilkesehatan-indonesia/profilkesehatan-indonesia-2006.pdf pada tanggal 2 Mei 2018.

[2] Departemen Kesehatan, RI. (2013). RisetKesehatan Dasar (RISKESDAS 2013).Jakarta : Departemen Kesehatan

[3] Direktorat Jenderal Pendidikan Dasar Kementerian Pendidikan dan Kebudayaan Rebuplik Indonesia. (2014). Pedoman Pelaksanaan UKS di Sekolah.
Diakses secara online melalui https://kupdf.com/queue/pedoma n-pelaksanaan-uks-di-sekolah-

2014 pdf 58a9353b6454a73b08b1e8ef pdf?queue $i d=1 \& x=1525507243 \&$ $\mathrm{z}=$ MjEwLjU3LjIxNS4xOTg = pada tanggal 5 Mei 2018.

[4] Kementerian Pendidikan dan kebudayaan Direktorat Jenderal Pendidikan Dasar. (2014). Pedoman Pelaksanaan UKS di Sekolah. Diakses secara online melalui kupdf.com pedomanpelaksanaan-uks-di-sekolah-

2014pdf pada tanggal 12 April 2018.

[5] Kementerian Kesehatan Republik Indonesia. (2011). Profil Kesehatan Indonesia. Diakses secara online melalui

https://kupdf.com/queue/pedoma n-pelaksanaan-uks-di-sekolah-

2014pdf 58a9353b6454a73b08b1e8ef pdf?queue id $=1 \& x=1525507243 \&$ $\mathrm{z}=$ MjEwLjU3LjIxNS4xOTg $=$ pada tanggal 5 Mei 2018.

[6] Kementerian Kesehatan Republik Indonesia. (2009). Undang-Undang Republik Indonesia Nomor 36 Tahun 2009 tentang Kesehatan.

[7] Larasanti, Adi. (2017). Pelaksanaan Promosi Kesehatan Rumah Sakit Di RSU Haji Surabaya. Diakses secara online melalui https://ejournal.unair.ac.id/PROMKES/artic le/view/7701. Universitas Airlangga, Surabaya. Indonesia pada tanggal 5 Mei 2018.

[8] Notoatmodjo, S. 2010. IImu Perilaku Kesehatan. Jakarta: Rineka Cipta

[9] Rompas, Sefti., dkk. (2014). Pengaruh Pendidikan Kesehatan Terhadap Tingkat Pengetahuan dan Sikap Remaja tentang Penyakit 
Menular Seksual di SMK Fajar Bolaang Mongondow Timur. Diakses secara online melalui https://ejournal.unsrat.ac.id/index .php/ikp/article/view/5225 pada tanggal 20 Agustus 2018.
[10] WHO. (1986). Ottawa Charter for Health Promotion, International Conference on Health Promotion. Diakses secara online melalui http://www.who.int/healthpromo tion/en/ pada tanggal 5 Mei 2018. 